\title{
The Mechanism of the Selective Fe-Catalyzed Arene Carbon- Hydrogen Bond Functionalization
}

\author{
Verònica Postils, ${ }^{\dagger, \ddagger}$ Mònica Rodríguez, ${ }^{\dagger, \ddagger}$ Gerard Sabenya ${ }^{\dagger}$ Ana Conde, ${ }^{\S}$ M. Mar Díaz-Requejo, ${ }^{\S}, *$ \\ Pedro J. Pérez, ${ }^{\S, *}$ Miquel Costas, ${ }^{\dagger, *}$ Miquel Solà, ${ }^{\dagger} * *$ and Josep M. Luis ${ }^{\dagger, *}$ \\ †Institut de Química Computacional i Catàlisi (IQCC) and Departament de Química, Universitat de Girona, Campus Montili- \\ vi, 17071, Girona, Spain \\ ${ }^{\S}$ Laboratorio de Catálisis Homogénea, Unidad Asociada al CSIC, CIQSO-Centro de Investigación en Química Sostenible and \\ Departamento de Química, Universidad de Huelva, 21007 Huelva, Spain
}

ABSTRACT: The complete chemoselective functionalization of aromatic $\mathrm{C}\left(\mathrm{sp}^{2}\right)-\mathrm{H}$ bonds of benzene and alkyl-benzenes by carbene insertion from ethyl diazoacetate was unknown until the recent discovery of an iron-based catalytic system toward such transformation. A Fe(II) complex bearing the pytacn ligand (pytacn=L1=1-(2-pyridylmethyl)-4,7-dimethyl-1,4,7-triazacyclononane) transferred the $\mathrm{CHCO}_{2} \mathrm{Et}$ unit exclusively to the $\mathrm{C}\left(\mathrm{sp}^{2}\right)-\mathrm{H}$ bond. The cycloheptatriene compound commonly observed through Buchner reaction or, when employing alkyl-benzenes, the corresponding derivatives from $\mathrm{C}\left(\mathrm{sp}^{3}\right)$ - $\mathrm{H}$ functionalization are not formed. We herein present a combined experimental and computational mechanistic study to explain this exceptional selectivity. Our computational study reveals that the key step is the formation of an enol-like substrate, which is the precursor of the final insertion products. Experimental evidences based on substrate probes and isotopic labelling experiments in favor of this mechanistic interpretation are provided.

KEYWORDS carbene transfer iron catalysis $\mathrm{C}-\mathrm{H}$ activation $\mathrm{C}\left(\mathrm{sp}^{2}\right)-\mathrm{H}$ functionalization DFT calculations

\section{INTRODUCTION}

The metal-catalyzed carbene transfer from a diazo reagent to $\mathrm{C}-\mathrm{H}$ bonds constitutes a strategy that is gaining interest in the last decade. ${ }^{1}$ Both $\mathrm{C}\left(\mathrm{sp}^{2}\right)-\mathrm{H}$ and $\mathrm{C}\left(\mathrm{sp}^{3}\right)-\mathrm{H}$ bonds can be modified by this methodology, albeit when working with benzene derivatives the issue of selectivity emerges as a serious drawback. This is the consequence of a series of competing reactions that may occur, as shown in Scheme 1. The addition of the carbene unit to a $\mathrm{C}=\mathrm{C}$ bond of the arene leads to a norcaradiene intermediate that spontaneously converts into the cycloheptatriene derivative, the addition product. This is the

Scheme 1. Possible products in the metal catalyzed (alkyl)-benzene functionalization by carbene insertion

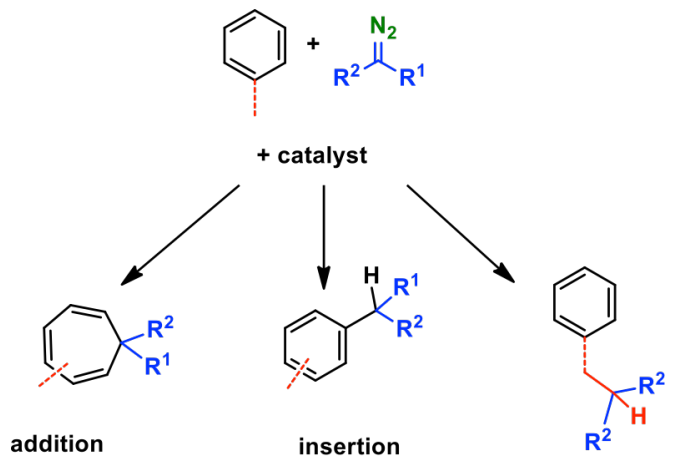

so-called Buchner reaction, known in a thermal manner since the XIX century, ${ }^{2}$ and in the rhodium-catalyzed version after the work by Noels and co-workers. ${ }^{3}$ The second transformation is that of the neat insertion ${ }^{4}$ of the carbene unit in the $\mathrm{C}\left(\mathrm{sp}^{2}\right)-\mathrm{H}$ bond of the arene, a less frequent transformation. To date the functionalization of benzene and other nonsubstituted arenes by this methodology based on metalcarbene intermediates, generated from diazo reagents, has been achieved using several metals (Scheme 2) such as rhodium, ${ }^{5}$ or coinage metals. ${ }^{6,7}$ In all these cases, a mixture of products is obtained due to the existence of aforementioned competing reactions (Scheme 1). Until recently, the best selectivity for insertion as opposed to addition products is ca $3: 1$ (Scheme 2a), and was obtained with a gold-based catalyst. ${ }^{7} \mathrm{~A}$ chemoselective insertion of the carbene group in aromatic $\mathrm{C}\left(\mathrm{sp}^{2}\right)-\mathrm{H}$ bonds can be achieved with the use of electron-rich benzene derivatives such as phenol or anisole (Scheme $2 b$ ). The addition of these $\pi$-electron-donating groups $(-\mathrm{OH}$, $\left.-\mathrm{OCH}_{3}\right)$ to benzene enhances the nucleophilic reactivity of the aromatic carbons and favors insertion products. ${ }^{8}$ The use of electron-deficient phosphite ligands increases the electrophilic character of the carbene moiety in gold catalysts, enabling selective insertion in electron-rich arenes. Finally, the existence of alkyl-substituents ${ }^{9}$ or other $\mathrm{X}-\mathrm{H}$ groups $(\mathrm{X}=\mathrm{O}, \mathrm{H})^{10}$ in the substrate may lead to their functionalization, also upon insertion of the carbene group. These substrate functionalization reactions also compete with the non-productive metalcatalyzed coupling of two carbene units. ${ }^{11}$ 
Scheme 2. Functionalization of arenes by metal-carbene catalysts.

a) Non-activated benzene and non-chemoselective process

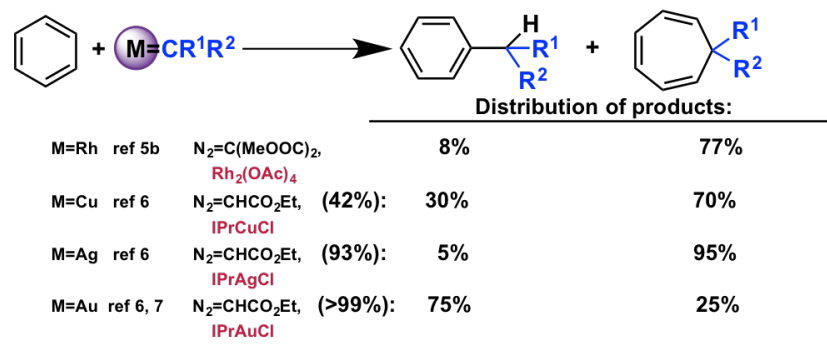

b) Activated benzene (phenol) and chemoselective processes

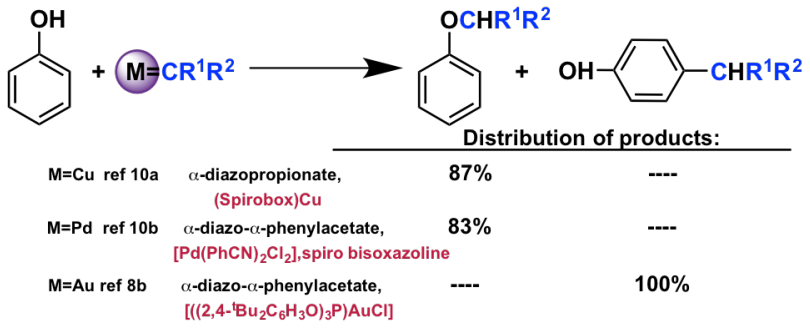

c) Non-activated benzene and chemoselective processes

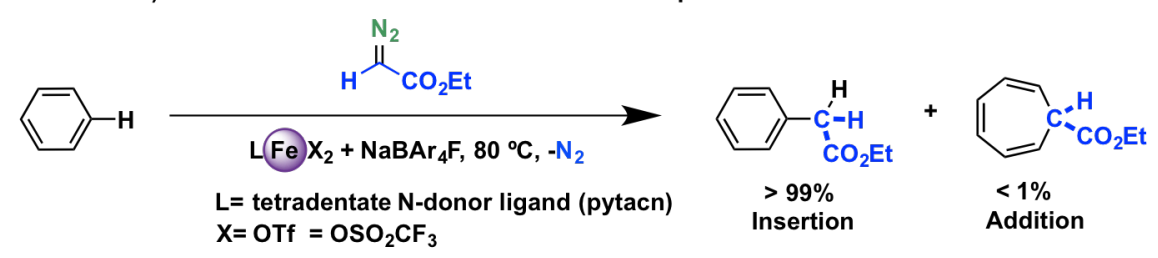

a) Precedents in the catalytic functionalization of benzene by metal-carbene transfer. Non-chemoselective processes. b) Precedents in the functionalization of activated benzenes (phenol) by metal-carbene transfer. Chemoselective processes. c) Reaction of this study. First example of a chemoselective functionalization of benzene.

Recently, we reported the first example for a chemoselective functionalization of non-activated aryl $\mathrm{C}\left(\mathrm{sp}^{2}\right)-\mathrm{H}$ bonds with the use of the commercially available ethyl diazoacetate (EDA) and iron- or manganese-based catalysts. ${ }^{12} \mathrm{Fe}^{\mathrm{II}}$ and $\mathrm{Mn}^{\mathrm{II}}$ complexes bearing the tetradentate pytacn ligand (pytacn $=\mathrm{L} 1$ $=1$-(2-pyridylmethyl)-4,7-dimethyl-1,4,7-triazacyclononane) lead to $>99 \%$ formation of insertion products and no formation of cycloheptatriene derivatives (Scheme 2c). Fumarate and maleate products, resulting from coupling of two carbene units, were also practically absent. This work also expanded to first-row transition metal catalysts the direct functionalization of non-activated aryl $\mathrm{C}\left(\mathrm{sp}^{2}\right)-\mathrm{H}$ bonds by metal-carbene transfer from ethyl diazoacetate. Interestingly, the presence of substituents in a series of alkyl-aromatic substrates did not affect the selectivity of the reaction, since the alkylic $\mathrm{C}-\mathrm{H}$ bonds remained unreacted, only the aryl $\mathrm{C}-\mathrm{H}$ bonds being functionalized. In view of the novelty of this transformation in terms of the exceptional selectivity, we have performed a combined experimental and theoretical study that has led to the understanding of the mechanistic details of the functionalization of $\mathrm{C}-\mathrm{H}$ bond of benzene, which may serve in the design of novel generations of catalysts with improved efficiency and chemoselectivity.

\section{RESULTS AND DISCUSSION}

\section{Experimental analyses}

Effect of the catalyst architecture in the catalytic activity. Initially we studied the potential ability of iron complexes to catalyze the reaction of ethyl diazoacetate (EDA) and benzene (Scheme 2c and Table 1). Reactions were performed at $80^{\circ} \mathrm{C}$ during $12 \mathrm{~h}$ in a $1: 1$ mixture of benzene and $\mathrm{CH}_{2} \mathrm{Cl}_{2}$ under $\mathrm{N}_{2}$, and were initiated by the addition of 20 equiv of EDA to a solution of $5 \mathrm{~mol} \%$ of the catalyst and $\mathrm{NaBAr}_{4}{ }^{\mathrm{F}}$ (2-8 equiv). Reactions provided insertion (I) and addition (A) products, and the yields and relative amount of both products were dependent on the catalyst. The typology of the catalysts studied in our previous work was mainly focused in tetradentate aminopyridine ligand (Scheme 3 ), which have proven to form iron complexes particularly active in oxygen atom transfer reactions (L1 and L7 constitute prototypical examples). ${ }^{13}$ In the current work, this collection has been extended with the use of iron complexes bearing sterically encumbered tridentate (L10) and tetradentate (L9) ligands based in pyrazole rings, and that have been found particularly active in other carbene transfer reactions with first row transition metals. ${ }^{14}$ This analysis reinforces $\left[\mathrm{FeX}_{2}(\mathrm{~L} 1)\right]$ (where $\mathrm{X}=\mathrm{Cl}$ or OTf) as a particularly efficient (entries 1 and 2, up to $86 \%$ of EDA was converted into products) and chemoselective catalysts towards the insertion product $(>99 \%)$. Modifications in the electron donating properties of the pyridine (entries 3-6), and in the denticity of the ligand (entries 7 and 9) led to lower product yields. Particularly noticeable was the observation that complex $[\mathrm{Fe}(\mathrm{OTf})(\mathrm{L} 8)](\mathrm{OTf})$, bearing a pentadentate ligand, was inactive (entry 9), strongly suggesting that the presence of two labile sites at the first coordination sphere of the iron center is necessary for activity. Complexes based in pyrazolyl donors, $\left[\mathrm{Fe}(\mathrm{OTf})_{2}(\mathrm{~L} 9)\right]$ and $[\mathrm{Fe}(\mathrm{OTf})(\mathrm{L} 10)]$ are active (entries 10 and 11) but provide roughly 1:1 mixtures of insertion and addition products.

On the basis of the previous observations, $\left[\mathrm{Fe}(\mathrm{OTf})_{2}(\mathrm{~L} 1)\right]$ was taken as the catalyst of choice to test other carbene sources, that led to limited success (entries 12 and 13). Unlike EDA, which provides insertion products in good yield and selectivity, the use of phenyldiazoacetate of its 4-bromo de- 
rivative resulted instead in a slight preference towards the expansion product in moderate (41-51\%) yields.

Table 1. Catalytic behavior of different $\left[\mathrm{FeX}_{2}(\mathrm{~L})\right]$ complexes in the reaction of benzene and ethyl diazoacetate. ${ }^{\mathrm{a}}$

\begin{tabular}{lccccc}
\hline Entry & L & X & Yield $^{\mathrm{b}}$ & ${\text { \%l: } \% \mathrm{~A}^{\mathrm{c}, \mathrm{d}}}^{2}$ & Ref \\
\hline 1 & L1 & Cl & 86 & $>99: 1$ & 12 \\
2 & L1 & OTf & 83 & $>99: 1$ & 12 \\
3 & L2 & OTf & 77 & $>99: 1$ & 12 \\
\hline 4 & L3 & OTf & 47 & $>99: 1$ & 12 \\
\hline 5 & L4 & OTf & 85 & $>99: 1$ & 12 \\
6 & L5 & OTf & 18 & $>99: 1$ & 12 \\
7 & L6 & OTf & 67 & $>99: 1$ & 12 \\
8 & L7 & OTf & 70 & $>99: 1$ & 12 \\
9 & L8 & OTf & n.r & $\ldots$ & 12 \\
\hline 10 & L9 & Cl & 57 & $42: 58$ & This work \\
11 & L10 & Cl & 55 & $53: 47$ & This work \\
12 & L1 & OTf & 41 & $45: 55^{\mathrm{f}}$ & This work \\
\hline 13 & L1 & OTf & 51 & $40: 60^{\mathrm{g}}$ & This work \\
\hline
\end{tabular}

${ }^{\mathrm{a}}$ Reactions carried out at $80^{\circ} \mathrm{C}$ with $0.005 \mathrm{mmol}$ of catalyst, 8 equiv of $\mathrm{NaBAr}_{4}{ }^{\mathrm{F}}$ and 20 equiv of ethyl diazoacetate in $1.5 \mathrm{~mL}$ of benzene $+1.5 \mathrm{~mL}$ of $\mathrm{CH}_{2} \mathrm{Cl}_{2}$. Reaction time: $12 \mathrm{~h}$. ${ }^{\mathrm{b}}$ Initial EDA converted into insertion $(I)+$ addition $(A)$ products. Determined by GC; some ethyl glycolate from adventitious water was detected as byproduct. ${ }^{\mathrm{c}}$ Determined by NMR. ${ }^{\mathrm{d}}$ The acid-catalyzed conversion of $A$ into $I$ has been discarded on the basis of blank experiment: see Supporting Information. ${ }^{\mathrm{e}} \mathrm{FeX}[\mathrm{L} 10]$ complex ${ }^{\mathrm{f}}$ Phenyldiazoacetate was used as carbene source instead of EDA. ${ }^{\mathrm{g}} 4-\mathrm{Br}-$ phenyldiazoacetate was used as carbene source instead of EDA.

Scheme 3. Complexes employed as catalyst precursors in the screening shown in Table 1.

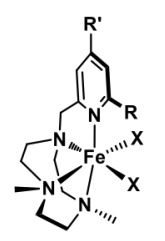

$\mathbf{R}=\mathbf{H}, \mathbf{R}^{\prime}=\mathbf{H},\left[\mathrm{FeX}_{2}(\mathrm{~L} 1)\right]$ $R=M e, R^{\prime}=H,\left[F e X_{2}(L 2)\right]$ $R=H, R^{\prime}=\mathrm{tBu},\left[\mathrm{FeX}_{2}(\mathrm{~L} 3)\right]$ $\mathrm{R}=\mathrm{H}, \mathrm{R}^{\prime}=\mathrm{Cl},\left[\mathrm{FeX}_{2}(\mathrm{~L} 4)\right]$ $\mathrm{R}=\mathrm{H}, \mathrm{R}^{\prime}=\mathrm{CF}_{3},\left[\mathrm{FeX}_{2}(\mathrm{~L} 5)\right]$ $\mathrm{X}=\mathrm{Cl}, \mathrm{OSO}_{2} \mathrm{CF}_{3}$ (OTf)
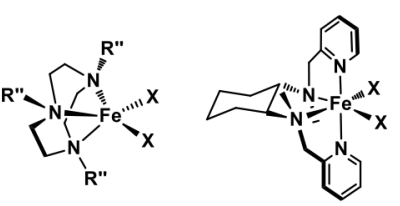

$\mathrm{R}^{\prime \prime}=\mathrm{IBu}^{\mathrm{B}}\left[\mathrm{FeX}_{2}(\mathrm{L6})\right]$

$\left[\mathrm{FeX}_{2}(\mathbf{L} \mathbf{7})\right]$

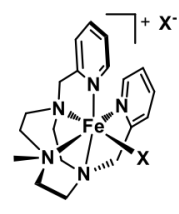

$\left[\mathrm{FeX}_{2}(\mathrm{LB})\right]$
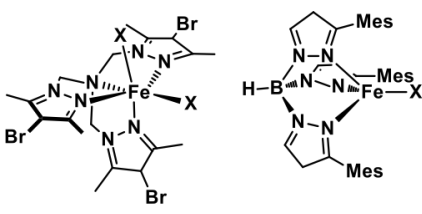

$\left[\mathrm{FeX}_{2}\right.$ (L9)]

[FeX(L10)]
Considering that 2-8 equivalents of $\mathrm{NaBAr}_{4}{ }^{\mathrm{F}}$ are necessary for efficient activity, we investigated the iron species that are formed when this salt reacts with $\left[\mathrm{Fe}(\mathrm{OTf})_{2}(\mathrm{~L} 1)\right]$. Diiron complex $\left[\mathrm{Fe}_{2}\left(\mu^{2} \text {-OTf }\right)_{2}(\mathrm{~L} 1)_{2}\right]\left(\mathrm{BAr}_{4}{ }^{\mathrm{F}}\right)_{2}$, was prepared by reaction of $\left[\mathrm{Fe}(\mathrm{OTf})_{2}(\mathrm{~L} 1)\right]$ with 1-4 equiv. of $\mathrm{NaBAr}_{4}{ }^{\mathrm{F}}$, and it was crystallographically characterized. An ORTEP diagram of the diiron complex is shown in Figure 1, and compared with that of $\left[\mathrm{Fe}(\mathrm{OTf})_{2}(\mathrm{~L} 1)\right] .{ }^{15}$ Iron centers in both complexes are coordinatively saturated. They have a distorted octahedral coordination geometry, with four sites occupied by the L1 ligand and the two remaining sites fulfilled by oxygen atoms of the triflate ligands, which are terminally coordinated in the mononuclear complex and bridging in the dinuclear case.

When $\left[\mathrm{Fe}(\mathrm{OTf})_{2}(\mathrm{~L} 1)\right]$ complex was tested under standard reaction conditions, but in the absence of additional $\mathrm{NaBAr}_{4}{ }^{\mathrm{F}}$, it was catalytically inactive. However, when the same reaction was conducted in the presence of 4 equiv. of $\mathrm{NaBAr}_{4}{ }^{\mathrm{F}}$, the insertion product was obtained as the only product in $80 \%$ yield. These observations strongly suggest that detachment of the first triflate anion from $\left[\mathrm{Fe}(\mathrm{OTf})_{2}(\mathrm{~L} 1)\right]$ does not lead to an active catalyst, and instead removal of the two anionic ligands, generating two vacant sites at the iron coordination sphere, are most likely needed for EDA activation. Unfortunately, iron species resulting from elimination of the second triflate ligand could not be isolated, and the paramagnetic nature of the iron species makes ${ }^{1} \mathrm{H}-\mathrm{NMR}$ ineffective to probe its formation in solution. However, prominent ions at $\mathrm{m} / \mathrm{z}=$ 152.1 with isotopic patterns characteristic of $[\mathrm{FeL} 1)]^{2+}$ could be observed in the ESI-MS spectra of $\left[\mathrm{Fe}(\mathrm{OTf})_{2}(\mathrm{~L} 1)\right]$, suggesting that tetracoordinate dicationic species are viable intermediates.
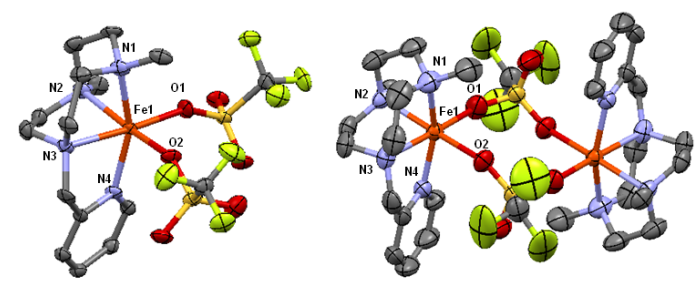

Figure 1. ORTEP diagram of the single crystal X-ray structure for $\left[\mathrm{Fe}(\mathrm{OTf})_{2}(\mathrm{~L} 1)\right]$ (left) and $\left[\mathrm{Fe}_{2}\left(\mu^{2}-\mathrm{OTf}\right)_{2}(\mathrm{~L} 1)_{2}\right]\left(\mathrm{BAr}_{4}{ }^{\mathrm{F}}\right)_{2}$ (right).15 50\% ellipsoid probability, $\mathrm{H}$ atoms have been omitted for clarity. $\left[\mathrm{Fe}(\mathrm{OTf})_{2}(\mathrm{~L} 1)\right]$ selected distances $(\AA)$ : Fe1-N1: 2.231, Fe1-N2: 2.251, Fe1-N3: 2.205, Fe1-N4: 2.165, Fe1-O1: 2.055, Fe1-O2: 2.165. $\left[\mathrm{Fe}_{2}(\mu-\mathrm{OTf})_{2}(\mathrm{~L} 1)_{2}\right]\left(\mathrm{BAr}_{4}{ }^{\mathrm{F}}\right)_{2}$ selected distances $(\AA)$ : Fe1-N1: 2.200, Fe1-N2: 2.210, Fe1-N3: 2.187, Fe1-N4: 2.142, Fe1-O1: 2.060, Fe1-O2: 2.189.

The results collected in this section reveal that $\left[\mathrm{Fe}(\mathrm{OTf})_{2}(\mathrm{~L} 1)\right]$ is a particularly efficient and chemoselective catalyst for the formal carbene insertion from EDA into the $\mathrm{C}$ $\mathrm{H}$ bonds of benzene, reinforcing the findings of the preliminary communication. ${ }^{12}$ It is worth noting that the scope of this catalytic system with a series of substituted benzenes showed the complete selectivity toward such bonds in the presence of alkyl C-H sites of the substituents. The presence of two labile coordination sites appears to be necessary for efficient catalysis.

Mechanistic considerations from product analysis. Our previous contribution included ${ }^{12}$ a Hammett analysis of the carbene transfer reaction, determined by means of competitive 
functionalization of pairs of monosubstituted arenes, which provided $\rho=-2.75 \pm 0.37$, indicative of an electrophilic functionalization of the arene. Furthermore, an inverse intermolecular $\mathrm{KIE}=0.95$ was determined, consistent with a change in the hybridization from $\mathrm{sp}^{2}$ to $\mathrm{sp}^{3}$ in the arene functionalization step. These parameters strongly suggest that the functionalization of the arene occurs via an electrophilic aromatic substitution, a proposal that is in good concordance with the $o: m: p$ ratios observed in the functionalization of monosubstituted benzenes. We have now collected additional pieces of information en route to mechanism elucidation.

Scheme 4. Alkyl migrations in the functionalization of 1,3,5-trialkylsubstituted arenes.

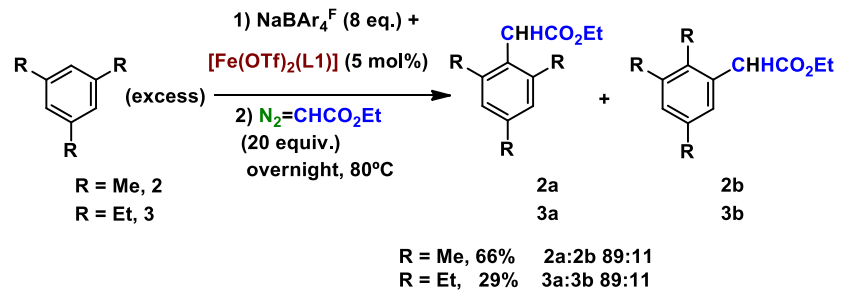

Alkyl group migrations. Functionalization of mesitylene (2) and 1,3,5-triethylbenzene (3) under standard reaction conditions (Scheme 4) provides the ethyl esters $\mathbf{2 a}$ and 3a as major products resulting from a formal insertion at arene $\mathrm{C}-\mathrm{H}$ bond. However, inspection of the reaction crude NMR spectra reveal the formation of a minor product $\mathbf{2 b}$ and $\mathbf{3 b}$, respectively $(\sim 11 \%)$ resulting from alkyl migration.

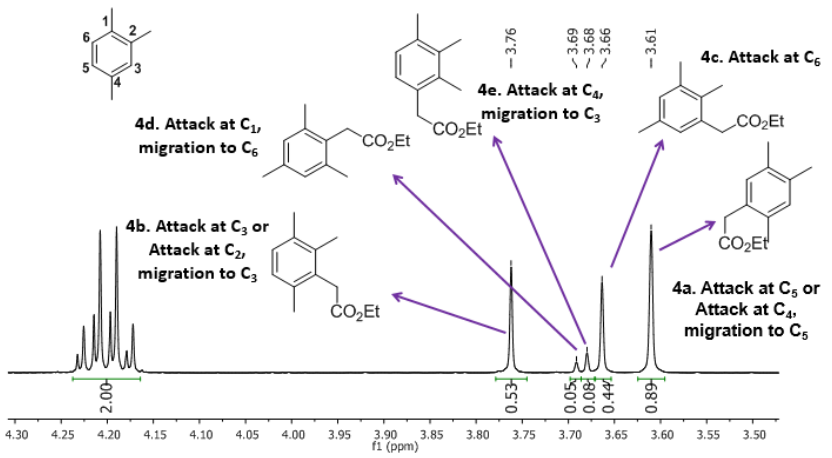

Figure 2. ${ }^{1} \mathrm{H}-\mathrm{NMR}$ spectrum $\left(\mathrm{CDCl}_{3}, 400 \mathrm{MHz}, 300 \mathrm{k}\right)$ of the EDA insertion products obtained in the functionalization of $\mathbf{4}$ with $\left[\mathrm{Fe}(\mathrm{OTf})_{2}(\mathrm{~L} 1)\right]$. The origin of the different products is indicated in each case.

Alkyl migrations are best evidenced by performing the functionalization of 1,2,4-trimethylbenzene (4) under standard reaction conditions (Figure 2$)$. The reaction produced three major (4a, 4b and 4c) and two minor (4d and 4e) products. Major products originate from formal carbene insertion in $\mathrm{C}$ $\mathrm{H}$ bonds at $\mathrm{C}_{5}, \mathrm{C}_{3}$ and $\mathrm{C}_{6}$, respectively, while minor products are indicative of insertions accompanied by alkyl migrations. 4d can be explained based on an initial attack at $C_{1}$, followed by methyl migration to $\mathrm{C}_{6}$, while $4 \mathbf{e}$ indicates initial attack on $\mathrm{C}_{4}$ followed by methyl migration to $\mathrm{C}_{3}$. Of these, $4 \mathrm{a}$ appears as the major product, presumably because: i) $\mathrm{C}_{5}$ and $\mathrm{C}_{6}$ are sterically less congested than $\mathrm{C}_{3}$; and ii) $\mathrm{C}_{5}$ is preferentially activated towards an electrophilic attack because it is in para position with respect to the methyl group at $\mathrm{C}_{2}$. We note that $\mathbf{4 b}, \mathbf{4 c}, 4 \mathbf{d}$ and $4 \mathbf{e}$ may be also at least partially originating from reactions where methyl migration takes place (see Figure 2).

Scheme 5. Carbene insertion into radical-clock substrate probes.

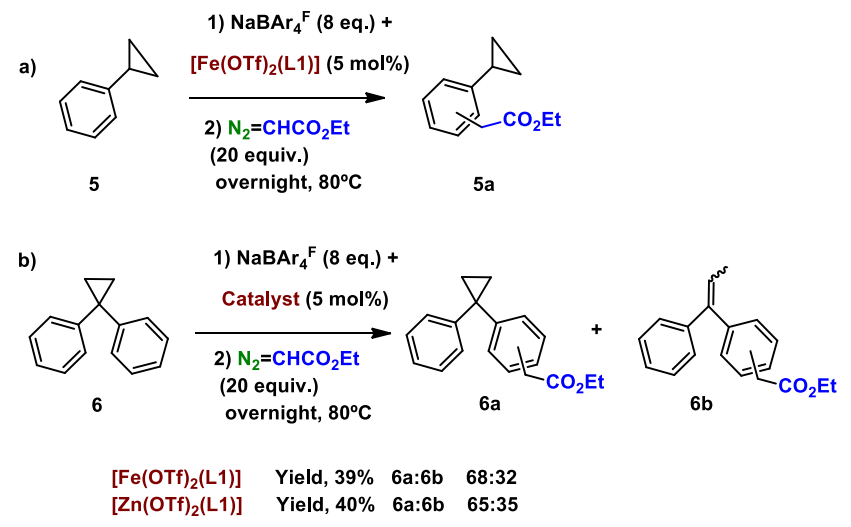

Radical clock substrate probes. An experiment of this type was provided in our previous report, where we described that the functionalization of cyclopropylbenzene (5) with $\left[\mathrm{Fe}(\mathrm{OTf})_{2}(\mathrm{~L} 1)\right]$ proceeds without ring opening (Scheme 5a). This experiment suggested that radical intermediates were not formed, or alternatively they must have very short lifetimes, incompatible with radical rearrangements. To further substantiate this point, an ultrafast radical probe (6, Scheme 5 b) was subjected to standard reaction conditions, employing the same catalysts. The reaction produced not-rearranged cyclopropyl product $\mathbf{6 a}$, and rearranged product $\mathbf{6 b}$ in a 68:32 ratio, with a combined $39 \%$ yield. This observation may initially suggest that the reaction proceeds via short living carbocationic or radical intermediates. Most remarkably, an almost identical ratio (65:35) and yield (40\%) was obtained when $\left[\mathrm{Zn}(\mathrm{OTf})_{2}(\mathrm{~L} 1)\right]$ was used as catalyst (see Supporting Information), suggesting that carbocationic and not radical rearrangements are involved. ${ }^{16}$

These results demonstrate that the reaction mechanism for carbene insertion must accommodate reaction intermediates susceptible to engage alkyl arene migrations and carbocationic rearrangements. Indeed, we notice that migrations may be also indicative of carbocationic intermediates.

Isotopic labelling analyses. Isotopic labelling analyses has revealed valuable mechanistic details in order to validate the computational analysis that follows. Under standard reaction conditions, formal carbene transfer to $1,3,5-\mathrm{D}_{3}$-benzene $\mathbf{D}_{\mathbf{3}} \mathbf{- 1}$ yields $\mathbf{D}_{\mathbf{3}} \mathbf{- 1} \mathbf{a}$, resulting from formal carbene insertion into an arene $\mathrm{C}-\mathrm{H}$ bond, and $\mathbf{D}_{\mathbf{3}} \mathbf{- 1} \mathbf{b}$, where insertion has occurred at the $\mathrm{C}-\mathrm{D}$ bond (Scheme 6a). The ratio of insertion vs. expansion is higher than $99 \%$, indicating that the deuteration of benzene does not change the chemoselectivity of the catalysis. Interestingly, partially D atom ends up forming the benzylic C-D bond in the $\mathbf{D}_{\mathbf{3}}-\mathbf{1 b}$ product. A $8 \%$ of the D is incorporated 
in the product, with the remaining corresponding to the fully hydrogenated benzylic position, suggesting the possibility of the incorporation of protons from an external source. The ratio between the two mentioned products is 49.3:50.7 (extracted from relative integration of the aromatic signals), which translates into an intramolecular kinetic isotope effect, $\mathrm{KIE}=0.97$, in agreement with the intermolecular KIE previously determined from the competitive functionalization of benzene and $\mathrm{D}_{6}$-benzene. Noticeable, products resulting from deuterium migration in the aromatic ring, analogous to those observed from alkyl groups, are not observed.

Finally, when the functionalization of benzene was conducted in the presence of $\mathrm{D}_{2} \mathrm{O}$ ( 0.25 equiv.), $42 \%$ of the corresponding benzyl ester product 1a contains a benzylic C-D group (Scheme 6b). Control experiments showed that the benzylic $\mathrm{C}-\mathrm{H}$ bonds in 1a does not exchange the hydrogen atoms with $\mathrm{D}_{2} \mathrm{O}$. Consequently, these experiments indicate that the carbene transfer reaction involves species that could exchange an $\mathrm{H}$ atom with $\mathrm{D}_{2} \mathrm{O}$. The involvement of adventitious water in these transformations with gold-catalysts has been recently proposed. ${ }^{6}$

\section{Scheme 6. Isotopic labelling analysis.}

a)

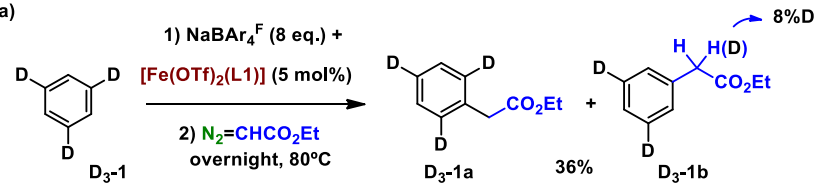

b)

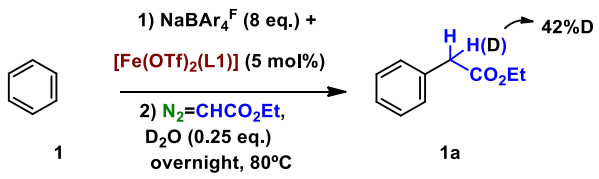

The above reactivity implies that the mechanism of carbene insertion must accommodate a path that enables the transfer of an arene hydrogen atom to the benzylic position, and partial exchange of a benzylic $\mathrm{C}-\mathrm{H}$ bond with external water molecules.

\section{Computational analyses}

Generation of the carbene moiety. It is widely accepted that the most feasible reaction of metal catalysts with EDA proceeds via $\mathrm{N}_{2}$ loss to form a metal-carbene species. ${ }^{17} \mathrm{We}$ have studied the mechanism of this reaction for $\left[\mathrm{Fe}(\mathrm{OTf})_{2}(\mathrm{~L} 1)\right]$, taking into account the singlet, triplet, and quintet spin states. "Since the experimental data shows that the diiron complex $\left[\mathrm{Fe}_{2}\left(\mu^{2}-\mathrm{OTf}\right)_{2}(\mathrm{~L} 1)_{2}\right]^{2+}$ does not participate in the activation of EDA, it was not considered in the computational analyses" All structures were optimized and characterized at the UB3LYP-D3BJ/6-31G(d)/SMD(CH2C12) level of theory. Then, the electronic energies were improved performing single point calculations at the UB3LYP-D3BJ/ccpVTZ/SMD $(50 \% \mathrm{Bz}, 50 \% \mathrm{CH} 2 \mathrm{Cl} 2)$ level (more details about computational details can be found in the SI).

Based on the previously described experimental data, which suggests that the two triflate ligands are removed in the catalytically active species, two possible $[(\mathrm{L}) \mathrm{Fe}-(\mathrm{EDA})]^{2+}$ adducts have been characterized depending on which atom of EDA interacts with the iron (Figure 3). The carbonyl O-bound adduct $\mathbf{A}$ is the most stable form, while the carbon-bound adduct $\mathbf{A}^{\prime}$ is $14.2 \mathrm{kcal} / \mathrm{mol}$ higher in energy. Then, the most stable adduct is given by the interaction between the iron and the most nucleophilic atom of EDA. The nitrogen-bound adduct has not been characterized as a stable minima, as opposite to other metal catalysts interacting with EDA. ${ }^{18}$ For $[\mathrm{Fe}(\mathrm{L} 1)]^{2+}$ and all EDA-bound adducts, the most stable spin state is the quintet (see Figure $\mathrm{S} 1$ for more details).

Only the $\mathbf{A}^{\prime}$ adduct is able to evolve, via $\mathrm{N}_{2}$ elimination, towards the formation of the Fe-carbene moiety. The relative instability of $\mathbf{A}^{\prime}$ with respect to $\mathbf{A}$ leads to a global energy barrier of $29.5 \mathrm{kcal} / \mathrm{mol}$ for the overall reaction (Figure 3). Although an energy barrier of $29.5 \mathrm{kcal} / \mathrm{mol}$ is not affordable at room temperature, it can be overcome from ca. $80^{\circ} \mathrm{C}$, which is the experimental working temperature. High-energy barriers for carbene formation were also found for the formation of iron and cobalt porphyrin carbenes. ${ }^{19}$ This, along with the formation of the iron-carbene in the rate-determining step of the overall reaction of benzene functionalization, prevents the accumulation and experimental characterization of the putative iron-carbene or any other intermediate. Thus, the computational study becomes necessary for a proper mechanistic description.

Once the transition state (TS) for the $\mathrm{S}=2$ carbene formation ( $\left.\mathbf{T S}_{\mathbf{A}^{\prime}-\mathbf{C} @ \mathbf{N} 2}\right)$ is surmounted, a spin crossing takes place and triplet becomes the most stable spin state for the adduct between the Fe-carbene and $\mathrm{N}_{2}\left(\mathbf{C} @ \mathbf{N}_{2}\right)$. Finally, the loss of the $\mathrm{N}_{2}$ moiety is favorable and the global carbene formation process (A to $\mathbf{C}$ ) is endoergic by $4.9 \mathrm{kcal} / \mathrm{mol}$. A quasi-equivalent $\mathbf{C} @ \mathbf{N}_{\mathbf{2}}$ isomer is obtained if EDA is coordinated to the labile position perpendicular to the pyridyl ring instead of the parallel one (see Figure S2).

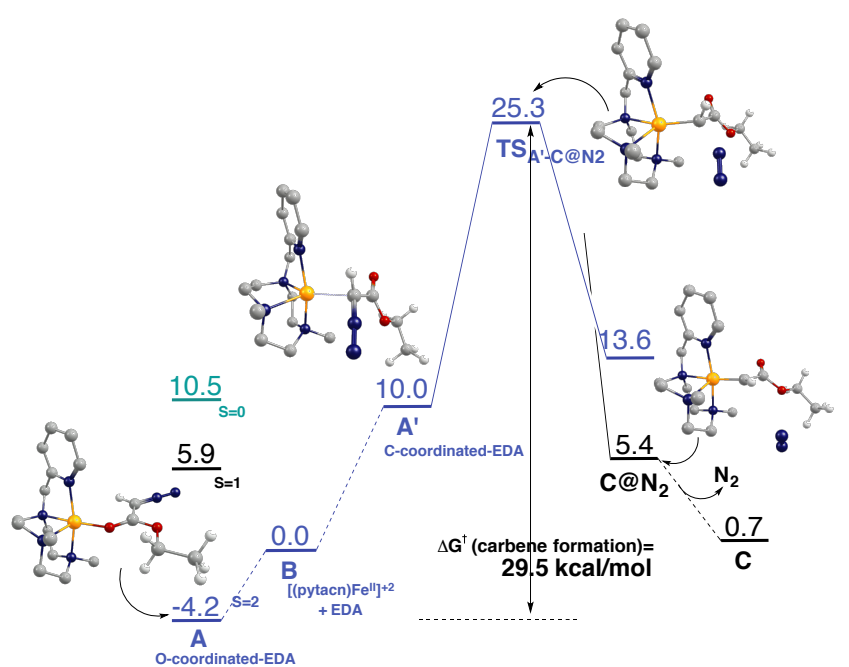

Figure 3. Gibbs energy profile, $\Delta \mathrm{G},\left(\mathrm{kcal} \cdot \mathrm{mol}^{-1}\right)$ of the metal-carbene bond formation. Blue, black and green profiles correspond to quintet, triplet and singlet multiplicities, respectively. Hydrogen atoms of L1 ligand have been omitted for clarity (C: grey, N: blue, O: red, Fe: yellow, H: white). 


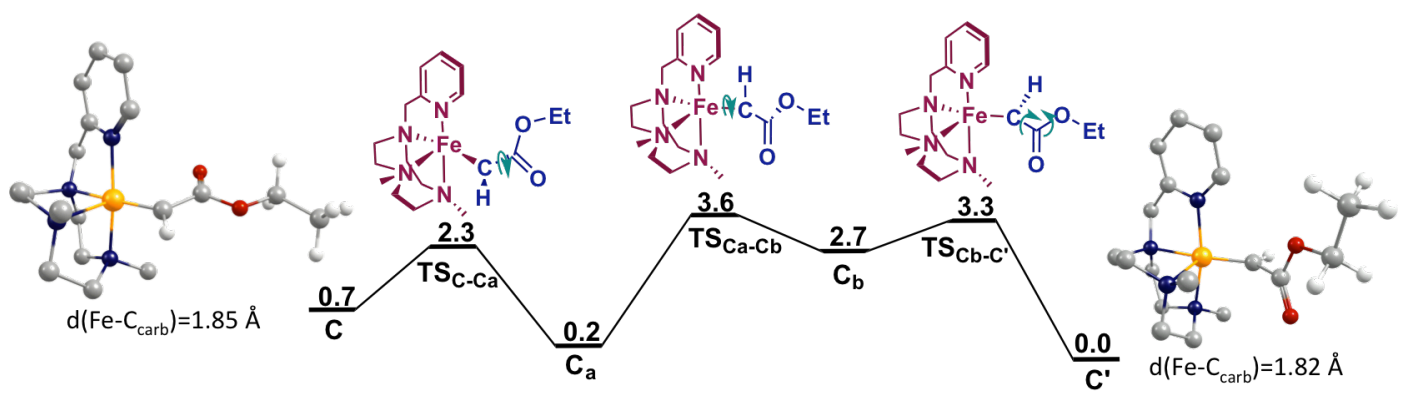

Figure 4. Gibbs energy profile, $\Delta \mathrm{G}\left(\mathrm{kcal} \cdot \mathrm{mol}^{-1}\right)$ of the $\mathbf{C}$-to- $\mathbf{C}^{\prime}$ conformational change at the triplet spin state. For $\mathbf{C}$ and $\mathbf{C}^{\prime}$ intermediates, the $\mathrm{Fe}-\mathrm{C}$ bond distance is given in $\AA$. Hydrogen atoms of the L1 ligand have been omitted for clarity (C: grey, N: blue, O: red, Fe: yellow, H: white).

The metal center in the iron-carbene species $(\mathbf{C})$ displays a distorted octahedral coordination geometry, with one freecoordination site and five occupied-coordination sites taken by the tetradentate ligand and the carbene. The $\mathrm{Fe}-\mathrm{C}_{\text {carbene }}$ distance in $\mathbf{C}$ is $1.85 \AA$ (Figure 4). Iron-carbene bond lengths are sensitive to the electronic nature and chemical environments of the carbene and iron ligands. ${ }^{20}$ The DFT analyses of the spin densities, frontier molecular orbitals (MOs), natural bond orbitals (NBO), ${ }^{21}$ and the effective oxidation states (effOS $)^{22}$ suggest that the electronic nature of $\mathbf{C ~ F e - c a r b e n e ~ i s ~}$ described as a $\mathrm{Fe}$ (III) and a formal radical alkyl substituent (see Supporting Information for details). An equivalent electronic structure was reported by Shaik et al. for an iron porphyrin carbene complex. ${ }^{17 \mathrm{~b}}$

Iron-carbene $\mathbf{C}$ is not the Fe-carbene conformer that presents the lowest barrier to react with benzene. Among all the conformers analyzed, the C' conformer was found to be the most suitable for the approach of benzene to the $\mathrm{C}_{\text {carb }}$ and to facilitate further benzene functionalization reactions. The main difference between $\mathbf{C}$ and $\mathbf{C}^{\prime}$ is the position of the carbene tail (see Figure 4). While in the $\mathbf{C}$ conformer the carbon$\mathrm{yl}$ group is pointing towards the free-coordination site of the catalyst, in the $\mathbf{C}^{\prime}$ conformer, the tail of the carbene is bent towards the equatorial- $\mathrm{NCH}_{3}$ group of the ligand. Although in the $\mathbf{C}$ conformer the carbonyl oxygen of the carbene tail is pointing toward the free-coordination site of iron, on the basis of non-covalent interaction $(\mathrm{NCI})^{23}$ and $\mathrm{NBO}$ analysis, a bonding interaction between the carbonyl oxygen of the carbene tail and the iron atom is discarded (see Figure S6). Fur- thermore, NCI analyses evidence that the $\mathbf{C}^{\prime}$ conformer presents a less crowded environment than $\mathbf{C}$ for $\mathrm{C}_{\text {carb }}$ (see section 3.2 in SI for the detailed NCI analysis). Therefore, on the contrary to $\mathbf{C}, \mathbf{C}$ ' has enough vacant space to allow: i) the approach of benzene in front of the free-coordination site of the iron; and ii) the movement of the carbene hydrogen required for the interaction between benzene and $\mathrm{C}_{\text {carb }}$ (see Figure S7). Thus, the comparison between $\mathbf{C}$ and $\mathbf{C}$ ' also shows the essential role of the free-coordination site of the Fecarbene in the functionalization of benzene, which agrees with the experimental need to add more than 2 equivalents of $\mathrm{NaBAr}_{4}{ }^{\mathrm{F}}$ for the reaction to proceed. The excess of $\mathrm{NaBAr}_{4}{ }^{\mathrm{F}}$ ensures the formation of the initial dicationic species $[\mathrm{Fe}(\mathrm{L} 1)]^{2+}$ with two free coordination sites (complex B, Figure3), required for the formation of the metal-carbene.

The detailed pathway from $\mathbf{C}$ to $\mathbf{C}$ ' has been computationally studied and it is shown in Figure 4. The evolution contains several low-energy transition states connecting intermediates of similar energy that match up to three consecutive $\sigma$-bond rotations ${ }^{24}$ of: i) the bond of $\mathrm{C}_{\text {carb }}$ with the carbonyl carbon $\left(\mathbf{T S}_{\mathbf{C - C a}}\right)$, ii) the bond of $\mathrm{C}_{\text {carb }}$ with the iron $\left(\mathbf{T S}_{\mathbf{C a}-\mathbf{C b}}\right)$, and iii) again the bond of $\mathrm{C}_{\text {carb }}$ with the carbonyl carbon $\left(\mathbf{T S}_{\mathbf{C b}-\mathbf{C}}\right.$ ). $\mathbf{T S}_{\mathbf{C a - C b}}$ has the highest energy barrier of the conformational evolution, which is only $3.4 \mathrm{kcal} / \mathrm{mol}$. The $\mathrm{Fe}-\mathrm{C}_{\text {carb }}$ bond rotation and its low energy barrier are consistent with the existence of a very weak $\mathrm{Fe}-\mathrm{C}_{\text {carb }} \pi$-interaction. Apart from the key differences pointed above, conformers $\mathbf{C}$ and $\mathbf{C}^{\prime}$ have similar geometric and electronic structures (see SI for details).

\section{Scheme 7. Plausible pathways for the formation of insertion and addition products}

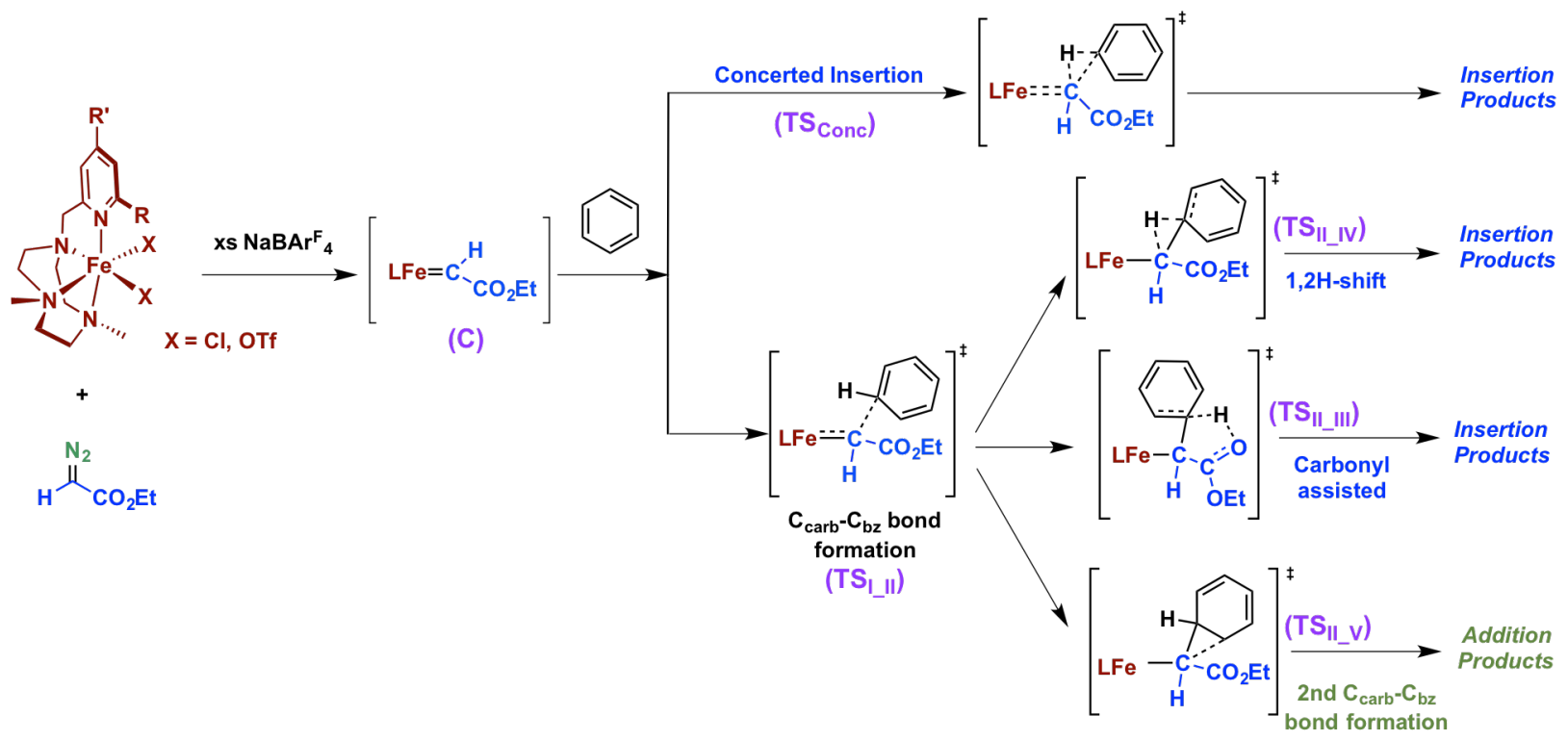


Mechanistic insights in benzene functionalization I. Concerted insertion versus stepwise mechanisms. Our study of the first step of the reaction between the iron-carbene and benzene has taken into account two different possible pathways: an stepwise mechanism and a concerted one (see Scheme 7 and Figure 5). In the former, the attack of the aromatic benzene $\mathrm{C}\left(\mathrm{sp}^{2}\right)$ to $\mathrm{C}_{\text {carb }}\left(\mathbf{T S}_{\mathbf{I}_{-} \mathrm{II}}\right)$ leads to an intermediate with a $\mathrm{C}_{\mathrm{carb}}-\mathrm{C}_{\mathrm{bz}}$ bond (II). The intermediate II can evolve through two different pathways to both possible final products, i.e. the insertion and expansion products (see next section). In the concerted mechanism, the attack of the aromatic benzene $\mathrm{C}\left(\mathrm{sp}^{2}\right)$ to $\mathrm{C}_{\text {carb }}\left(\mathbf{T S}_{\text {Conc }}\right)$ directly gives insertion products. Both pathways have been described in the literature on mechanisms of C-H bond insertion by metal-carbenes. ${ }^{25}$ The singlet, triplet, and quintuplet spin states were considered in the calculation of the Gibbs energy profile. Besides the study of the reaction of $\mathbf{C}^{\prime}$ with benzene that yields the adduct $\mathbf{I}$, it has also been considered the reaction of benzene with a bidentate carbene isomer $\left(\mathbf{I}^{\mathbf{k} 2}\right)$, which is $1.2 \mathrm{kcal} / \mathrm{mol}$ less stable than $\mathbf{I}$. The $\mathbf{I}^{\mathbf{K} 2}$ isomer with a singlet ground state can be understood as an evolution of carbene $\mathbf{C}$, where the carbonyl oxygen is bonded to iron through its sixth-coordination site. A global picture of the results is represented in Figure 5.

The most favorable mechanism for the initial step of the functionalization of benzene is the $\mathrm{C}_{\text {carb }}-\mathrm{C}_{\mathrm{bz}}$ bond formation

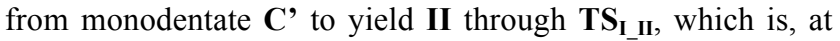
least, $8.5 \mathrm{kcal} / \mathrm{mol}$ lower in energy than any other studied pathway. This step has a global energy barrier of only 17.3 $\mathrm{kcal} / \mathrm{mol}$ whereas the same reaction mechanism for the bidentate carbene has an energy barrier of $25.9 \mathrm{kcal} / \mathrm{mol}\left(\mathbf{T S}^{\mathbf{K} 2}{ }_{\mathbf{I}} \mathrm{II}\right)$. Therefore, we discard any role of isomer $\mathbf{I}^{\mathbf{k} 2}$ in the functionalization of benzene (see Figures S10, S12, and S13 in the SI for geometry and electronic details of $\mathbf{T S}_{\mathbf{I}_{-} \text {II }}$ and $\mathbf{T} \mathbf{S}^{\mathbf{k} 2}{ }_{\text {I_II }}$ ).

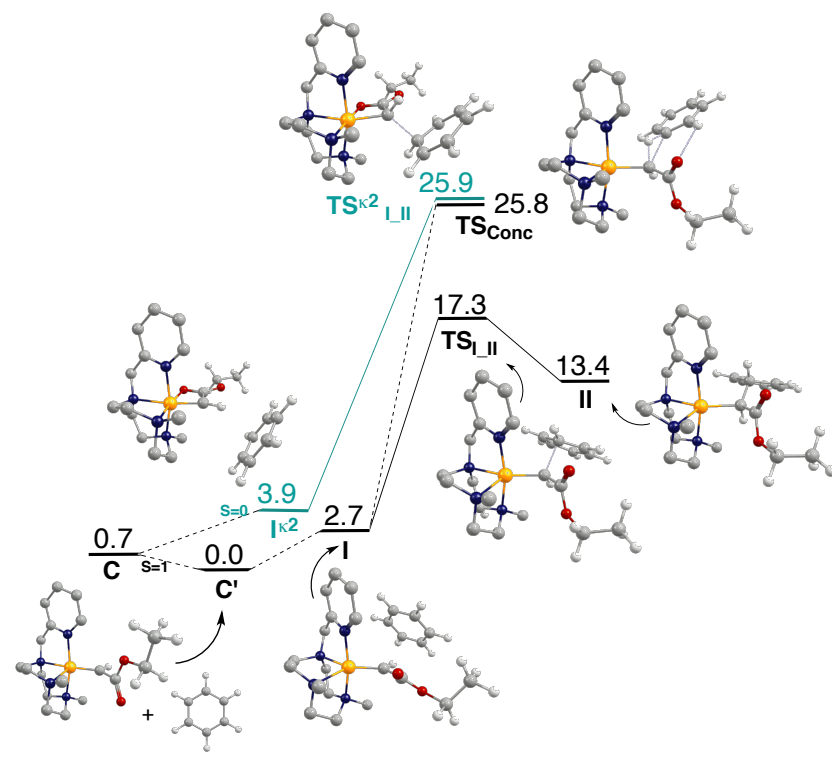

Figure 5. Comparative Gibbs energy profile, $\Delta \mathrm{G}$, $\left(\mathrm{kcal} \cdot \mathrm{mol}^{-1}\right)$ of the first steps of the studied reactions between benzene and the iron-carbene. Black and green profiles correspond to triplet and singlet multiplicities, respectively. Hydrogen atoms of the L1 ligand have been omitted for clarity $(\mathrm{C}$ : grey, $\mathrm{N}$ : blue, O: red, Fe: yellow, H: white).

For the concerted mechanism, a high-energy barrier of 25.8 $\mathrm{kcal} / \mathrm{mol}\left(\mathbf{T S}_{\mathbf{C o n c}}\right)$ at the triplet spin ground state is found. Thus, the concerted mechanism is also discarded. In agreement with our results, the fact that metal-carbenes do not perform a concerted $\mathrm{C}_{\text {substrate }}-\mathrm{H}$ bond insertion for aromatic substrates contrary to alkane substrates has been also recently reported for gold-carbenes. ${ }^{8 \mathrm{a}}$ The same conclusion can also be obtained comparing the mechanistic literature of the reactions of $\mathrm{Au}, \mathrm{Cu}, \mathrm{Ag}$ or $\mathrm{Rh}$ carbenes with alkanes ${ }^{26}$ and with aromatic compounds. ${ }^{6 \mathrm{a}, 25 \mathrm{~b}}$

DFT analysis of the electronic structure of intermediate II suggests a cyclohexadienyl radical character intermediate (see Table S7). However, several pieces of experimental evidences point towards this reaction proceeding via an electrophilic attack of the carbene on the aromatic ring, generating a Wheland type intermediate. On one hand, o:m:p ratios and Hammett parameters are consistent with this scenario. On the other hand, the inverted KIE effect is in good agreement with $\mathrm{a} \mathrm{sp}^{2}$ to $\mathrm{sp}^{3}$ change in hybridization in the arene functionalization step. Furthermore, the cationic nature of the intermediate is well supported by the observation of alkyl migration products, and by the carbocationic rearrangement product obtained in the functionalization of the ultrafast radical probe $\mathbf{6}$. The degree of reorganization of this substrate is identical to that measured with the red-ox inactive $\left[\mathrm{Zn}(\mathrm{OTf})_{2}(\mathrm{~L} 1)\right]$ catalyst, providing strong argumentation against a radical electronic structure of II. The radical electronic structure of ${ }^{3} \mathbf{I I}$ predicted by DFT calculations could be due to the particular strong spin contamination of the wavefunction of intermediate ${ }^{3}$ II (i.e. $<\mathrm{S}^{2}>=3.1$ ). Nevertheless, it is important to remark here that we have used the Yamaguchi correction ${ }^{27}$ to remove the spincontamination error of the computed Gibbs energies used to determine the most favorable mechanism (see Computational Details and Section 6 in the SI. Several conformers for all the reaction pathways and $S=0, S=1$, and $S=2$ spin states were examined. Figure 5 just shows the most important results and the complete data is shown in Figure S11 and Tables S4, S5 and S6. Emphasis had been placed on a proper description of the energy barrier and spin splitting of the $\mathrm{C}_{\mathrm{carb}}-\mathrm{C}_{\mathrm{bz}}$ bond formation $\left({ }^{\mathbf{3}} \mathbf{T S}_{\mathbf{I}_{\text {II }}}\right.$ and $\left.{ }^{\mathbf{5}} \mathbf{T} \mathbf{S}_{\mathbf{I}_{\text {III }}}\right)$. Thus, although the precise electronic structure of intermediate ${ }^{3} \mathbf{I I}$ is not exactly described by our methodology, additional calculations (vide infra) indicate that the Gibbs barrier of the transformation of I to II through ${ }^{3} \mathbf{T S}_{\mathbf{I}_{\text {III }}}$ is properly estimated.

It has to be mentioned here that ${ }^{\mathbf{5}} \mathbf{T S}_{\mathbf{I}_{-} \text {II }}$ is found to be 7.8 $\mathrm{kcal} / \mathrm{mol}$ lower in energy than ${ }^{\mathbf{3}} \mathbf{T S}_{\mathbf{I} \text { III }}$. However, we have not taken into account ${ }^{5} \mathbf{T S}_{\mathbf{I}_{-} \text {II }}$ in our mechanism for the reasons that follow. It is known that B3LYP is not a good functional to describe the correlation energy changes of reactions where the number of unpaired electrons of the metal-carbon bond changes. ${ }^{28}$ Furthermore, B3LYP tends to overstabilize the high-spin states. ${ }^{29}$ A study of homolytic Fe-, Co-, and Ni-C bond dissociation energies in tetra-pyrrole-like systems shows that the use of pure DFT methods with Becke's exchange functionals (BP86, BLYP or BPW91) are a better alternative than B3LYP to describe the metal-C bond breaking. $28^{\mathrm{a}}$ Thus, we have optimized $\mathbf{I}$ and $\mathbf{T S}_{\mathbf{I}_{\mathbf{I}} \mathbf{I I}}$ for the triplet and quintet spin 
states using B3LYP, B3LYP*, OPBE, M06-L, BP86, BLYP, and BPW91 functionals and 6-31G(d), 6-311+G(d,p) and Def2-SVP basis sets (see Table S5 and S6 in the SI for details). The results obtained with the literature-recommended functionals for this step ${ }^{28}$ of the mechanism (i.e. BP86, BLYP and BPW91) are similar among them and indicate that the triplet state is the spin ground state for both $\mathbf{I}$ and $\mathbf{T S}_{\mathbf{I}_{\text {III }} \text {. Be- }}$ sides, the three recommended functionals lead to similar ${ }^{3} \mathbf{T S}_{\mathbf{I}_{\text {II II }}}$ energy barriers. Thus, according to these results, we do not consider the spin-crossing from ${ }^{3} \mathbf{T S}_{\mathbf{I}_{\text {III }}}$ to ${ }^{\mathbf{5}} \mathbf{T S}_{\mathbf{I}_{\text {III }} \text {. Howev- }}$ er, we keep B3LYP as the reference functional because hybrid methods like B3LYP are more reliable functionals to study the other steps of the mechanism that involve formation and breaking of bonds between $\mathrm{H}, \mathrm{C}$, and $\mathrm{O}$ atoms. ${ }^{30}$ For consistency, we have chosen the same functional, B3LYP, to present the results for all the steps of the mechanism.

Mechanistic Insights in the benzene functionalization II. Insertion versus Expansion mechanisms. In this section the mechanism that determines the complete selective insertion of $-\mathrm{C}(\mathrm{H}) \mathrm{CO}_{2}$ Et into benzene's $\mathrm{C}-\mathrm{H}$ bonds with no formation of cycloheptatriene byproducts is addressed. Figure 6 presents all the possible different mechanisms we found that connect intermediate II with insertion or addition products.

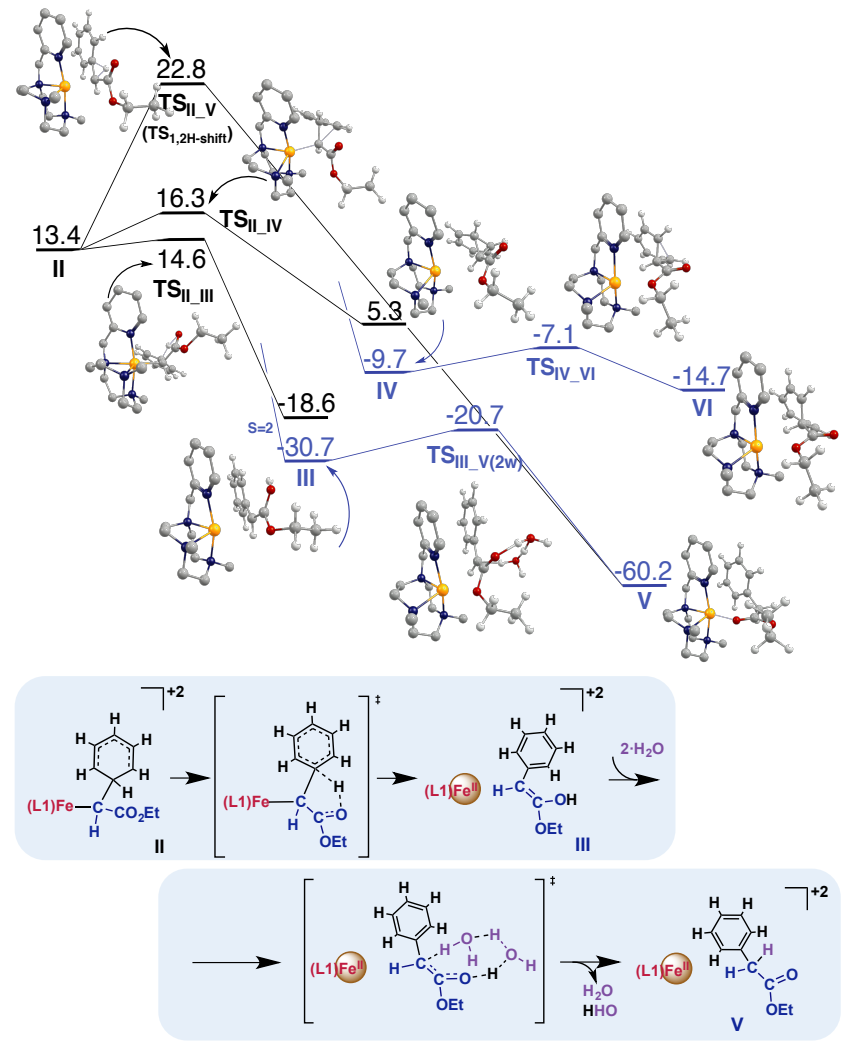

Figure 6. Comparative Gibbs energy profile, $\Delta \mathrm{G}$, $\left(\mathrm{kcal} \cdot \mathrm{mol}^{-1}\right)$ of the formation of addition (VI) and insertion (V) products from II. Black and blue profiles correspond to triplet and quintet multiplicities, respectively. Hydrogen atoms of the L1 ligand have been omitted for clarity (C: grey, N: blue, O: red, Fe: yellow, $\mathrm{H}$ : white). The inset below the energy profile details the reaction mechanism to obtain insertion products through the formation of the enol intermediate.
Two different pathways connect II with insertion products: i) the classical direct hydrogen migration between the two carbons that form the $\mathrm{C}_{\mathrm{carb}}-\mathrm{C}_{\mathrm{bz}}$ bond (i.e. from $\mathrm{C}_{\mathrm{bz}}$ to $\mathrm{C}_{\mathrm{carb}}$ ), the called [1,2]-H shift reaction $\left(\mathbf{T S}_{\mathrm{II}_{\mathbf{I}} \mathbf{v}}\right)$; and ii) a hydrogen abstraction reaction of the same hydrogen by the carbonyl oxygen of the native EDA ( $\mathbf{T S}_{\text {II_IIII }_{\text {III }}}$. The latter mechanism, named carbonyl assisted insertion, generates an enol intermediate that, to finally yield the insertion product, should subsequently evolve to the ester form. On the other hand, we only found one possible reaction that connects II with addition products. The addition pathway implies the formation of a second $\mathrm{C}_{\text {carb }}{ }^{-}$ $\mathrm{C}_{\mathrm{bz}}$ bond with an adjacent carbon of the phenyl ( $\left.\mathbf{T S}_{\text {II_IV }}\right)$. This TS does not directly give the addition product, but a norcaradiene, which can evolve to the final cycloheptatriene addition product (VI) through a thermally allowed electrocyclic disrotatory ring opening.

As it is shown in Figure 6, among the three different pathways that start at II, the formation of the enol is the lowest energy barrier process $\left(\mathbf{T S}_{\mathbf{I I}_{\mathbf{I I I}}}\right)$. The enol formation from II is strongly exergonic. Then, the next and last transition state of this pathway, the enol-to-ester transformation barrier, takes place at far lower Gibbs energy. Thus, the most favorable mechanism from II is the formation of the enol intermediate that leads to the final insertion of $-\mathrm{C}(\mathrm{H}) \mathrm{CO}_{2} \mathrm{Et}$ into benzene's $\mathrm{C}-\mathrm{H}$ bond. The abstraction of the hydrogen bonded to the phenylic carbon that forms the $\mathrm{C}_{\mathrm{carb}}-\mathrm{C}_{\mathrm{bz}}$ bond by one carbonyl oxygen has also been reported as the most favorable mechanism for the $\mathrm{C}-\mathrm{H}$ functionalization of arenes by $\mathrm{Au}$ and $\mathrm{Ag}$ carbene catalysts, , Error! Bookmark not defined. and in the functionalization of N-H bonds by Fe porphyrin carbene catalyst. ${ }^{19 \mathrm{~b}}$

The enol formation process has a small energy barrier of 1.2 $\mathrm{kcal} / \mathrm{mol}$. Although the enol product formed still remains close to iron (the $\mathrm{Fe}^{\cdots} \mathrm{C}$ distance is $2.28 \AA$ ), there is not a formal bond between them and iron is described as an $\mathrm{Fe}^{2+}\left(d^{6}\right)$. The enol intermediate structure III that involves a high spin $d^{6}$ iron with four unpaired electrons, ${ }^{5} \mathbf{I I I}$, is energetically more favorable than ${ }^{3}$ III by $12.1 \mathrm{kcal} / \mathrm{mol}$. Thus, a spin crossing takes places at this stage and the global process becomes highly exoergic $(44.1 \mathrm{kcal} / \mathrm{mol})$ because the benzyl group recovers the aromatic character.

The formation of the norcaradiene, the addition-product precursor, through $\mathbf{T S}_{\mathbf{I I}} \mathbf{I V}$ and the direct formation of the insertion product through the classical hydrogen migration from the phenylic carbon to the benzylic carbon, $\mathbf{T S}_{\mathbf{I I} \_} \mathbf{v}$, involve energy barriers of 2.9 and $9.4 \mathrm{kcal} / \mathrm{mol}$, respectively. Thus, both $\mathbf{T S}_{\text {II_IV }}$ and $\mathbf{T S}_{\text {II_V }}$ have higher energies than $\mathbf{T} \mathbf{S}_{\text {II_III }}$, which implies that these other two reactions will hardly take place. This result nicely agrees and explains the experimental data, which show that our Fe catalyst presents a clear selectivity for the generation of insertion products. It is worth noticing that, in electronic energy terms, the enol formation barrier is higher than the norcaradiene formation barrier. Then, entropy has a key effect favoring $\mathbf{T S}_{\text {II_III }}$ over $\mathbf{T} \mathbf{S}_{\text {II_IV }}$ due to the loose five-membered ring structure of $\mathbf{T S}_{\text {II III }}$ (see Table S8). When EDA is replaced by 4-Br-phenyldiazoacetate (entry 13 of Table 1), DFT barriers show that the chemoselectivity for the formation of insertion products decreases (see Table S11), in nice agreement with the experimental data and the reduction of the carbonyl group basicity of II. 
Both the norcaradiene-formation transition state and the $[1,2]-\mathrm{H}$ shift transition state imply the rearrangement reaction and the dissociation of the products formed. In $\mathbf{T S}_{\text {II_IV }}$, besides the substrate formation, norcaradiene decoordinates from the catalyst $\left(\mathrm{Fe}^{\cdots} \mathrm{C}_{\text {carb }}\right.$ distance of $\mathbf{I V}$ is $\left.3.30 \AA\right)$; and, in $\mathbf{T S}_{\mathbf{I I} \mathbf{V}}$, along with the substrate formation and decoordination $\left(\mathrm{Fe}{ }^{\cdots} \mathrm{C}_{\text {carb }}\right.$ distance of $\mathbf{V}$ is $\left.3.62 \AA\right)$, the formation of a new adduct between $\mathrm{Fe}$ and the oxygen atom of the carbonyl group of insertion products occurs $\left(\mathrm{Fe}^{\cdots} \mathrm{O}_{\text {carb }}\right.$ distance of $\mathbf{V}$ is $1.97 \AA)$. Despite the $\mathrm{Fe}^{\cdots} \mathrm{O}_{\text {carb }}$ interaction in $\mathbf{I V}$ and $\mathbf{V}$ products, iron recovers its $\mathrm{Fe}^{2+}\left(d^{6}\right)$ electronic configuration and, since the high spin state is the most stable spin case for $[\mathrm{Fe}(\mathrm{L} 1)]^{2+}\left(\mathrm{d}^{6}\right)$, a spin crossing from ${ }^{3} \mathbf{I V}\left({ }^{3} \mathbf{V}\right)$ to ${ }^{5} \mathbf{I V}\left({ }^{5} \mathbf{V}\right)$ arises.

The final steps from the norcaradiene intermediate, ${ }^{5} \mathbf{I V}$, to addition products, ${ }^{\mathbf{5}} \mathrm{VI}$, or from the enol intermediate, ${ }^{\mathbf{5}} \mathbf{I I I}$, to insertion products, ${ }^{5} \mathbf{V}$, imply low energy barriers. The ringexpansion reaction that gives the final cycloheptatriene product from norcaradiene intermediate involves a $2.6 \mathrm{kcal} / \mathrm{mol}$ energy barrier, ${ }^{5} \mathbf{T S}_{\mathbf{I V} \text { _VI }}$. On the other hand, the enol-ester tautomerism involves a $10.0 \mathrm{kcal} / \mathrm{mol}$ energy barrier when it is assisted by two water molecules, ${ }^{\mathbf{5}} \mathbf{T S}_{\text {III_v }}$. It is interesting to note that the water is essential to decrease the value of ${ }^{\mathbf{5}} \mathbf{T S}_{\text {III_V}}$, since the equivalent transition state Gibbs energy barrier without water has a value of ca. $46.6 \mathrm{kcal} / \mathrm{mol}$ (see Table S9 in the SI). Although water was not added in our experiments, the presence of adventitious water molecules was experimentally detected by the formation of certain amount of ethyl glycolate products. ${ }^{12}$

Most importantly, it must be noted that this mechanism accounts for the results on the isotopic labelling experiments; in first place, the hydrogen atom at the $\mathrm{C}-\mathrm{H}$ bond that suffers the attack of the carbene moiety can end up at the benzylic position of the product. In addition, the intermediacy of the enol provides a path for incorporation of hydrogen atoms from water in the final product.

\section{CONCLUSIONS}

The mechanism of the recently discovered iron-catalyzed selective functionalization of benzene upon carbene insertion from ethyl diazoacetate has been elucidated. The catalyst precursor $\left[\mathrm{Fe}(\mathrm{OTf})_{2}(\mathrm{~L} 1)\right]$ originates an electrophilic iron carbene intermediate that attacks the arene rendering a Wheland type intermediate that can engage in cationic rearrangements. Experimental data supports an electrophilic aromatic substitution behavior. A complementary computational analysis has demonstrated that the exquisite chemoselectivity towards the insertion product is rooted in the evolution of this intermediate via a facile hydrogen atom transfer from the arene to the carbonyl moiety of the carbene, forming an enol intermediate. DFT calculations show that the entropy is the driving force that induce the chemoselectivity of this catalyst for aryl $\mathrm{C}-\mathrm{H}$ insertion. Isotopic labelling analysis also provide credibility to this mechanism. Overall, the current study provides a mechanistic basis for understanding the unique chemoselectivity exhibited by this type of iron catalysts in carbene transfer reactions.

\section{ASSOCIATED CONTENT}

\section{Supporting Information}

Experimental procedures and DFT calculations are provided as a single pdf file. Cartesian coordinates of all computed structures are given in a separate text file in $x y z$ format. The Supporting Information is available free of charge on the ACS Publications website.

\section{AUTHOR INFORMATION}

\section{Corresponding Authors}

josepm.luis@udg.edu; miquel.sola@udg.edu; miquel.costas@ udg.edu; perez@dqcm.uhu.es; mmdiaz@dqcm.uhu.es.

\section{Present Addresses}

† Institut de Química Computacional i Catàlisi (IQCC) and Departament de Química, Universitat de Girona, Campus Montilivi, 17003 Girona (Spain).

$\S$ Laboratorio de Catálisis Homogénea, Unidad Asociada al CSIC, CIQSO-Centro de Investigación en Química Sostenible and Departamento de Química, Universidad de Huelva, Campus de El Carmen s/n, 21007 Huelva (Spain).

\section{Author Contributions}

$\$$ These authors equally contributed to this work.

\section{Funding Sources}

Support for this work was provided by the MINECO (CTQ201462234-EXP， CTQ2014-52769-C3-R-1， CTQ2014-54306-P, CTQ2014-52525-P, and grant No. BES-2012-052801 to V.P.), the Junta de Andalucía (P10-FQM-06292) and the Generalitat de Catalunya (Project 2014SGR931, Xarxa de Referència en Química Teòrica i Computacional, ICREA Academia prizes 2013 to M.C. and 2014 to M.S.). The EU under the FEDER grant UNGI10-4E-801 (European Fund for Regional Development) has also funded this research.

\section{REFERENCES}

(1) (a) Cheng, Q.-Q.; Doyle, M. P. Adv. Organomet. Chem. 2016, 66, 1-31. (b) Thumar, N. J.; Wei, Q. H.; Hu, W. H. Adv. Organomet. Chem. 2016, 66, 33-91; (c) Caballero, A.; Díaz-Requejo, M. M.; Fructos, M. R.,; Olmos, A.; Urbano, J.; Pérez, P. J. Dalton Trans. 2015, 44, 20295-20307; (d) Fructos, M. R.; Díaz-Requejo, M. M.; Pérez, P. J. Chem Commun 2016, 52, 7326-7335.

(2) Buchner, E.; Curtius, T. Beriche der Dtsch. Chem. Gesellschaft 1885, 18, 2371-2377.

(3) Anciaux, A. J.; Demonceau, A., Noels, A. F.; Hubert, A. J.; Warin, R.; Teyssie, P. H. J. Org. Chem. 1981, 46, 873-876.

(4) Given that the product obtained corresponds with that in which the carbene group has been inserted into the $\mathrm{C}-\mathrm{H}$ bond, we refer to this as the insertion product. However, the mechanism of this transformation does not necessarily takes place by an insertion step.

(5) (a) Rosenfeld, M. J.; Shankar, B. K. R.; Shechter, H. J. Org. Chem. 1988, 53, 2699-2705. (b) Yang, M.; Webb, T. R.; Livant, P. J. Org. Chem. 2001, 66, 4945-4949.

(6) Fructos, M. R.; Besora, M.; Braga, A. A. C.; Díaz-Requejo, M. M.; Maseras, F.; Pérez, P. J. Organometallics 2017, 36, 172-179. 
(7) (a) Fructos, M. R.; Belderrain, T. R.; de Frémont, P.; Scott, N M.; Nolan, S. P.; Díaz-Requejo, M. M.; Pérez, P. J. Angew. Chem. Int. Ed. 2005, 44, 5284-5288. (b) Rivilla, I.; Gómez-Emeterio, B. P.; Fructos, M. R.; Díaz-Requejo, M. M.; Pérez, P. J. Organometallics 2011, 30, 2855-2860.

(8) (a) Liu, Y.; Yu, Z.; Luo, Z.-L.; Zhang, J. Z.; Liu, L.; Xia, F. J. Phys. Chem. A 2016, 120, 1925-1932. (b) Yu, Z.; Ma, B.; Chen, M.; Wu, H.-H.; Liu, L.; Zhang, J. J. Am. Chem. Soc. 2014, 136, 6904 6907. (c)Xi, Y.; Su, Y.; Yu, Z.; Dong, B.; McClain, E. J.; Lan, Y.; Shi, X. Angew. Chem. Int. Ed. 2014, 53, 9817-9821

(9) (a) Callot, H. J.; Metz, F. Nov. J. Chem. 1985, 9, 167-171. (b) Davies, H. M. L.; Jin, Q. Tetrahedron Asymmetry 2003, 14, 941-949. (c) Davies, H. M. L.; Jin, Q.; Ren, P.; Kovalevsky, A. Y. J. Org Chem. 2002, 67, 4165-4169. (d) Morilla, M. E.; Díaz-Requejo, M. M.; Belderrain, T. R.; Nicasio, M. C.; Trofimenko, S.; Pérez, P. J. Organometallics 2004, 23, 293-295.

(10) (a) Osako, T.; Panichakul, D.; Uozumi, Y. Org. Lett. 2012, 14, 194-197. (b) Chen, C.; Zhu, S.-F.; Liu, B.; Wang, L.-X.; Zhou, Q.-L. J. Am. Chem. Soc. 2007, 129, 12616-12617. (c) Xie, X.-L.; Zhu, S.-F.; Guo, J.-X.; Cai, Y.; Zhou, Q.-L. Angew. Chem. Int. Ed. 2014, 53, 2978-2981. (d) Miura, T.; Zhao, Z.; Murakami, M. Angew. Chem. Int. Ed. 2017, 56, 16645-16649.

(11) Rivilla, I.; Sameera, W. M. C.; Alvarez, E.; Díaz-Requejo, M. M.; Maseras, F.; Pérez, P. J. Dalton Trans. 2013, 42, 4132-4138.

(12) Conde, A.; Sabenya, G.; Rodríguez, M.; Postils, V.; Luis, J. M.; Díaz-Requejo, M. M.; Costas, M.; Pérez, P. J. Angew. Chem. 2016, 128, 6640-6644.

(13) Codolà, Z.; Lloret-Fillol, J.; Costas, M. Prog. Inorg. Chem. 2014, 59, 447-532.

(14) (a) For trispyrazolylborate ligands see reference 1c. (b) For trispyrazolylamines see: Haldón, E.; Álvarez, E.; Nicasio, M. C.; Pérez, P. J. Chem. Commun., 2014, 50, 8978-8981.

(15) Company, A.; Gómez, L.; Güell, M.; Ribas, X.; Luis, J. M.; Que, L., Jr; Costas, M. J. Am. Chem. Soc. 2007, 129, 15766-15767.

(16) Kulkarni, N. V.; Dash, C.; Jayaratna, N. B.; Ridlen, S. G.; Khani, S. K.; Das, A.; Kou, S.; Yousufuddin, M.; Cundari, T. R.; Dias, H. V. R. Inorg. Chem. 2015, 54, 11043-11045.

(17) (a) Doyle, M. P.; Duffy, R.; Ratnikov, M.; Zhou, L. Chem. Rev. 2010, 110, 704-724. (b) Doyle, M. P.; McKervey, M. A.; Ye, T. Modern Catalytic Methods for Organic Synthesis with Diazo Compounds; Wiley: New York, 1998. (c) Davies, H. M. L.; Dick, A. R. Top. Curr. Chem. 2009, 292, 303-345. (d) Davies, H. M. L.; Manning, J. R. Nature 2008, 451, 417-424.

(18) (a) Dzik, W. I.; Xu, X.; Zhang, X. P.; Reek, J. N. H.; de Bruin, B. J. Am. Chem. Soc. 2010, 132, 10891-10902. (b) Pereira, A.;
Champouret, Y.; Martín, C.; Álvarez, E.; Etienne, E.; Belderraín, T. R.; Pérez, P. J. Chem. Eur. J. 2015, 21, 9769-9775.

(19) (a) Khade, R. L.; Zhang, Y. J. Am. Chem. Soc. 2015, 137, 7560-7563. (b) Sharon, D. A.; Mallick, D.; Wang, B.; Shaik, S. J. Am. Chem. Soc. 2016, 138, 9597-9610

(20) (a) Liu, Y.; Xu, W.; Zhang, J.; Fuller, W.; Schulz, C. E.; Li, J. J. Am. Chem. Soc. 2017, 139, 5023-5026. (b) Khade, R. L.; Fan, W.; Ling, Y.; Yang, L.; Oldfield, E.; Zhang, Y. Angew. Chem. Int. Ed. 2014, 53, 7574-7578. (c) Li, Y.; Huang, J.-S.; Zhou, Z.-Y.; Che, C.M.; You, X.-Z. J. Am. Chem. Soc. 2002, 124, 13185-13193.

(21) Weinhold, F.; Landis, C. R. Valency and bonding: a natural bond orbital donor-acceptor perspective; Cambridge University Press: Cambridge, U.K., 2005.

(22) (a) Ramos-Cordoba, E.; Postils, V.; Salvador, P. J. Chem. Theory Comput. 2015, 11, 1501-1508. (b) Skara, G.; Gimferrer, M.; De Proft, F.; Salvador, P.; Pinter, B. Inorg. Chem. 2016, 55, 21852199.

(23) Johnson, E. R.; Keinan, S.; Mori-Sánchez, P.; ContrerasGarcía, J.; Cohen. A. J.; Yang, W. J. Am. Chem. Soc., 2010, 132, 6498-6506.

(24) Lugan, N.; Fernández, I.; Brousses, R.; Valyaev, D. A.; Lavigne, G.; Ustynyuk, N. A.; Antipin, M. Y.; Ustynyuk, N. A. Dalton Trans. 2013, 42, 898-901

(25) (a) Padwa, A.; Austin, D. J.; Price, A. T.; Semones, M. A.; Doyle, M. P.; Protopopova, M. N.; Winchester, W. R.; Tran, A. $J$. Am. Chem. Soc. 1993, 115, 8669-8680. (b) Liu, Y.; Yu, Z.; Zhang, J. Z.; Liu, L.; Xia, F.; Zhang, J. Chem. Sci. 2016, 7, 1988-1995.

(26) (a) Braga, A. A. C.; Maseras, F.; Urbano, J.; Caballero, A.; Díaz-Requejo, M. M.; Pérez, P. J. Organometallics 2006, 25, 52925300. (b) Nakamura, E.; Yoshikai, N.; Yamanaka, M. J. Am. Chem. Soc. 2002, 124, 7181-7192. (b) Boultadakis-Arapinis, M.; Gandon, V.; Prost, E.; Micouin, L.; Lecourt, T. Adv. Synth. Catal. 2014, 356, 2493-2505.

(27) (a) Yamaguchi, K.; Jensen, F.; Dorigo, A.; Houk, K. N. Chem. Phys. Lett. 1988, 149, 537-542. (b) Wittbrodt, J. M.; Schlegel, H. B. J. Chem. Phys. 1996, 105, 6574-6577.

(28) (a) Jensen, K. P.; Ryde, U. J. Phys. Chem. A 2003, 107, 75397545. (b) Kuta, J.; Patchkovskii, S.; Zgierski, M. Z.; Kozlowski, P. M. J. Comput. Chem. 2006, 27, 1429-1437. (c) Qi, X.-J.; Li, Z.; Fu, Y.; Guo, Q.-X.; Liu, L. Organometallics 2008, 27, 2688-2698.

(29) (a) Swart, M.; Groenhof, A. R.; Ehlers, A. W.; Lammertsma, K. J. Phys. Chem. A 2004, 108, 5479-5483. (b) Güell, M.; Solà, M.; Swart, M. Polyhedron 2010, 29, 84-93.

(30) (a) Cohen, A. J.; Mori-Sánchez, P.; Yang, W. Chem. Rev. 2012, 112, 289-320. (b) Mangiatordi, G. F.; Brémond, E.; Adamo, C. J. Chem. Theory Comput. 2012, 8, 3082-3088. 


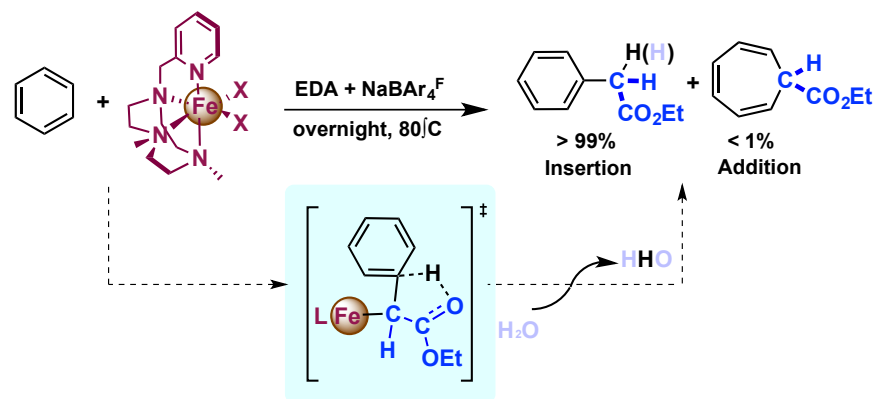

